\title{
Marilia Marchetti, Retorica e linguaggio nel secolo dei Lumi. Equilibrio logico e crisi dei valori
}

\section{Pierluigi Ligas}

\section{(2) OpenEdition}

1 Journals

\section{Édition électronique}

URL : https://journals.openedition.org/studifrancesi/39348

DOI : 10.4000/studifrancesi.39348

ISSN : 2427-5856

Éditeur

Rosenberg \& Sellier

\section{Édition imprimée}

Date de publication : 1 décembre 2004

Pagination : 366

ISSN : 0039-2944

\section{Référence électronique}

Pierluigi Ligas, «Marilia Marchetti, Retorica e linguaggio nel secolo dei Lumi. Equilibrio logico e crisi dei valori », Studi Francesi [En ligne], 143 (XLVIII | II) | 2004, mis en ligne le 30 novembre 2015, consulté le 19 mai 2021. URL : http://journals.openedition.org/studifrancesi/39348 ; DOI : https://doi.org/ 10.4000/studifrancesi.39348

Ce document a été généré automatiquement le 19 mai 2021.

\section{(c) $(1) \odot$}

Studi Francesi è distribuita con Licenza Creative Commons Attribuzione - Non commerciale - Non opere derivate 4.0 Internazionale. 


\title{
Marilia Marchetti, Retorica e linguaggio nel secolo dei Lumi. Equilibrio logico e crisi dei valori
}

\author{
Pierluigi Ligas
}

\section{RÉFÉRENCE}

MARILIA MARCHETTI, Retorica e linguaggio nel secolo dei Lumi. Equilibrio logico e crisi dei valori (Quaderni di cultura francese, a cura della Fondazione Primoli, Roma, Edizioni di Storia e Letteratura 2002, pp. 210.

1 Dans un court avant-propos, M. Marchetti annonce le contenu des six chapitres de son ouvrage - dont quelques-uns reprennent des travaux publiés précédemment - et élabore les définitions essentielles à la compréhension générale des thèmes abordés: du débat sur la langue tel qu'il se déroule dans les pages de l'Encyclopédie au discours révolutionnaire du «Pére Duchesne» en passant par le Dictionnaire philosophique de Voltaire, les Liaisons dangereuses de Choderlos de Laclos et les Victimes cloîtrées de Monvel. L'Auteur analyse d'abord les articles Langue et Grammaire de l' Encyclopédie, rédigés par Beauzée, puis les contributions de Beauzée lui-même et Du Marsais aux réflexions sur l'origine du langage, avant de passer à examiner les thèses de D'Alembert et Jaucourt, qui lui paraissent finalement assez proches. Dans le chapitre «Seduzione del Presente» M. Marchetti traite de la langue et des mots dans le Dictionnaire philosophique de Voltaire où, selon elle, perce la recherche d'une objectivité impartiale et où la raison apparaît comme l'ultime rempart contre la dégradation qui guette la langue. Mais alors qu'il ne montre aucun intérêt vis-a-vis d'une quelconque science du langage, precise l'Auteur, Voltaire exalte les modes d'expression de la tradition classique. Le chapitre troisième porte, quant à lui, sur ce que M. Marchetti appelle la «théorie de la traduction» et la «linguistique» des lumières. Aussi nous livre-t-elle un ensemble de remarques autour de l'Encyclopédie - de l'idée de «syntaxe» et de «traduction» chez Beauzée, Jaucourt, Marmontel et Du Marsais à l'article «traduction» 
- tout en recadrant ses réflexions sur l'horizon plus vaste de la diversité des langues et $\mathrm{du}$ rôle $\mathrm{du}$ traducteur. L'Auteur analyse ensuite un certain nombre de termes significatifs du vocabulaire français de la seconde moitié du XVIIIe siècle; pour ce faire, elle passe au crible les Liaisons dangereuses pour ensuite apporter un éclairage complémentaire particulièrement marquant sur les idées de style, de néologisme citations de Mercier et articles du Trésor de la langue française à l'appui - de jargon et de rhétorique libertine. Dans «Le théâtre de la Révolution», où il est principalement question de vocabulaire et d'ideologie, de «visibilité» et de «lumières», M. Marchetti aborde des termes tels que "plaisir», «amitié», «égalité», «citoyen», «liberté», «passion»... à partir des Victìmes cloitrées, le drame en prose qui, à son sens, «riassume e esemplifica [...] gli elementi caratterizzanti il teatro rivoluzionario». Le demier chapitre, «Retorica del lessico popolare», évoque le discours révolutionnaire du «Père Duchesne», notamment les procédés linguistiques, à savoir entre autres le recours systématique à la parodie, à l'amplification et à la grossièreté. Suit un appendice qui reprend les proverbes les plus significatifs et le vocabulaire adoptés par Hébert.

Une bibliographie riche et sélective ainsi qu'un très utile index des noms des personnes achèvent cet ouvrage bien redigé qui nous paraît obéir à un impératif majeur: prouver par des arguments pertinents que e'est bien au XVIIIe siècle que l'on assiste à la crise, puis à la fin de l'idée de langage comme «tableau spontané et quadrillage premier des choses», autrement dit à l'écroulement de tout un univers d'idées et de concepts lié à la Grammaire et à la Logique de Port-Royal. 